\title{
Contextualization of ICT Tools for Technological Surveillance Systems Associated with Innovation Processes
}

\author{
Luz Andrea Gaviria Roa \\ Universidad Internacional de La Rioja \\ Logroño, Spain \\ Henry Hernández Martínez, Holman Montiel Ariza ${ }^{1}$ \\ Universidad Distrital Francisco José de Caldas, Facultad Tecnológica \\ Cll 68 D Bis A Sur No. 49F - 70, Bogotá D.C., Colombia \\ ${ }^{1}$ hmontiela@udistrital.edu.co
}

\begin{abstract}
The constant change and transformation in organizations have made markets increasingly innovative and competitive, creating in this way the need to incorporate advanced technology to capture, process and analyze information from the current environment through the use of tools and / or instruments that facilitate decision making in an accurate way and even anticipate in their markets, making this a strategic increase for the organization. The objective of this paper is to carry out an analysis and contextualization in relation to Technological Surveillance Systems, with the purpose of exposing the characteristics and elements of management in the framework of technological surveillance. On the other hand, it will be introduced to the phases that make up a Technological Surveillance process, emphasizing the methodology for the selection of ICT / software tools. Finally, some of the existing tools in the market that allow successfully carry out each of the phases of this process are described.
\end{abstract}

Keyword-Technological surveillance system, surveillance tools, technological surveillance process, organizational innovation.

\section{INTRODUCTION}

Currently there are systems capable of collecting and providing information instantly with which it is possible to perform trend analysis allowing an evaluation of the market in just a short time and thus be able to anticipate the decision making process. Since technology advances considerably, it is necessary to be continuously updated regarding the systems or tools that provide such service, as the Technological Surveillance Systems, which in a summarized way can be defined as compilers of information that are in charge of obtaining and processing all the knowledge that circulates in relation to the interests of an organization.

Therefore, Technological Surveillance Systems are systems that are permanently monitoring and processing content from information sources [1]. Some of the meanings given for technological surveillance refer to this as:

- Organized and selective process of capturing information from abroad and from the organization itself.

- Methodology or procedure that allows obtaining the information that the organization seeks to make formal, rigorous and orderly decisions.

- Early warning system for risks, threats, but also for opportunities and detection of needs.

- Internal and external information search system.

But the most important thing and to which it points everything is that the technological surveillance is a continuous process that allows to improve the competitiveness and create business opportunities through the use of ICT tools that help the organizational management [2-3]. At the same time, identifying and implementing a technological surveillance system in an organization is linked to developing a process in which a series of phases are stipulated (identifying needs, obtaining, analyzing and valuing information, subsequently using it and finally protecting the results) that are addressed in a sequential manner until surveillance is achieved, without falling into the conception of espionage, since this process of obtaining information from different sources and the treatment of it until a final report is obtained that collects all the results, must be done in an ethical, responsible and legal manner so as not to incur any crime [4].

\section{METHODOLOGY}

The development of this paper initially contemplates the description of the characteristics associated with the technological surveillance systems, then the elements required in the management of the same are addressed and therefore an analysis is made of some of the ICT tools used for the development and achievement with notable benefits in a surveillance process [5-6]. 


\section{A. Features}

»Observe the environment with the purpose of having information.

»They are continuous in the surveillance and processing of information.

»They are based on computerized programs.

»They are implemented according to the needs of organizations.

»High degree of autonomy in its functions.

»They help to mark the directions of the strategies and projects of the organizations so that they can become business opportunities.

»Filtering, interpreting and valuing information to make the most accurate and effective decisions.

\section{B. Required elements in the management}

"Access to online databases, scientific publications, industrial and intellectual property, products on the market, calls, public and administrative information, etc.

»Personal prepared, with ICT capabilities and with technical knowledge in the areas of the organization.

»Design of a particular methodology for collecting and storing information.

»Development of software tailored to the needs based on descriptors and data semantics.

»Internal experts and external support for the analysis of information.

»Personnel responsible for the system, who are responsible for distributing the information to the rest of the people of the organization so that they consider the most appropriate within their areas of work.

C. ICT tools for technology surveillance

Currently in the market is a variety of tools that provide various features to organizations in relation to issues of technology monitoring [7], some of these are addressed below, in order to give an overview of each of these platforms (See Fig. 1).

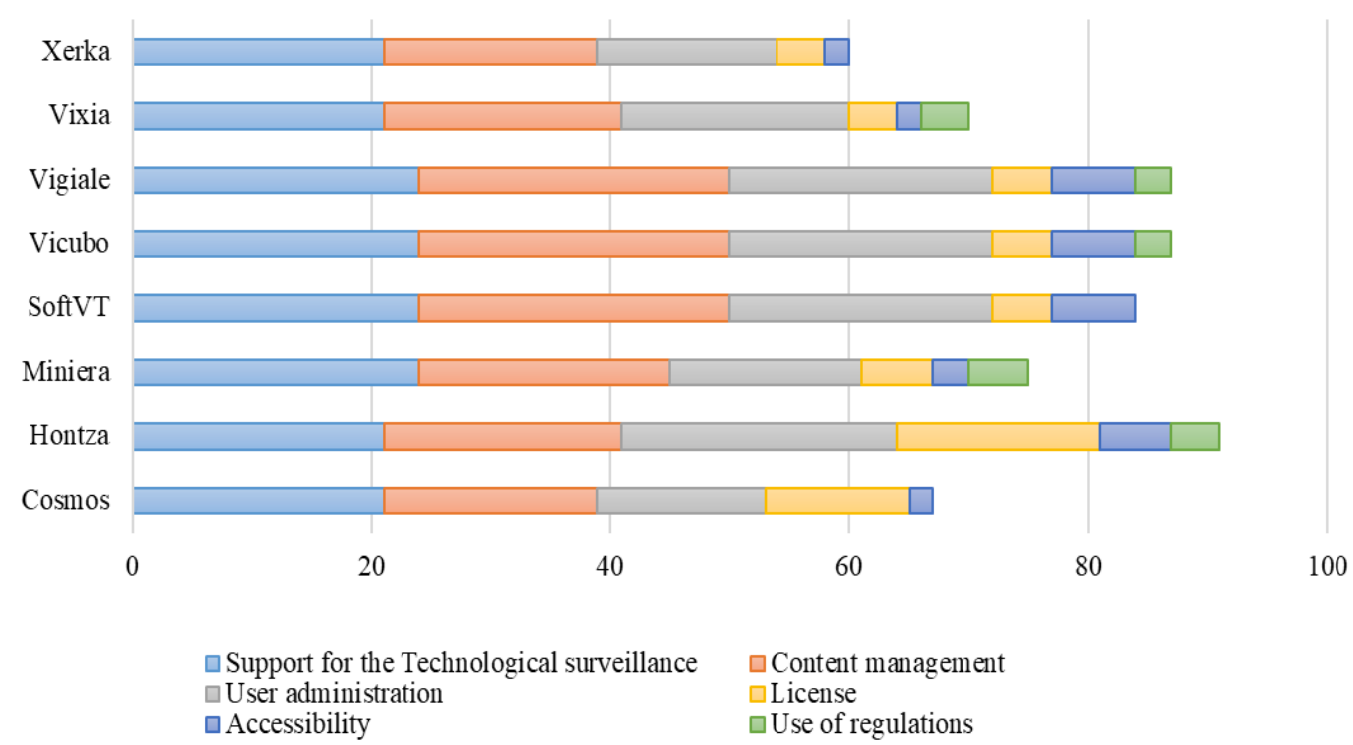

Fig. 1. Comparison of web tools for technological surveillance - Adapted from [10]

Xerka: Platform that automatically monitors the appearance of new information of interest to the company is based on the Software as a Service (SaaS) modality, so it does not require any additional infrastructure, only equipment with an internet connection.

Vixia: Integrated technological surveillance system that monitors and automates the processes of capture, treatment and analysis of information.

Vigiale: This tool allows you to manage different sources of information in an integrated way, order them, classify them and update them, using modern capture, categorization, indexing and filtering technologies of different nature; It consists of 3 independent applications (Vigiale Explorer, Vigiale Watcher and Vigiale Reporter), which focus on the different phases of the surveillance process.

Vicubo: Tool composed of several integrated modules; that allow systematizing, organizing and streamlining the monitoring process and competitive intelligence, under the UNE 166.006: 2011 standard. 
SoftVT: Software that allows processes of both technological surveillance and competitive intelligence, created to automate those processes related to the capture, management and dissemination of strategic information.

Miniera: Scalable platform in which the capture, validation and purification of information can be managed, the analysis of selected data and the creation of bulletins and alerts for users responsible for monitoring the desired items.

Hontza: It is a tool that allows the integral management of the surveillance process, with a target more focused on the group than on the individual user. It is based on a collaborative work style, and on the human analysis of information through filtering, scoring, labeling, comments, forums and wikis.

Cosmos: This platform focuses mainly on the search and information gathering phase of the technology surveillance process.

In the same way, it is necessary to be clear about exactly what is the search for, that is, to guide and use a methodology (See Fig. 2) that allows defining a series of steps to be followed in an orderly manner and thus opting for the most convenient and practical tools from which it is possible to obtain the greatest benefit. [4-10]

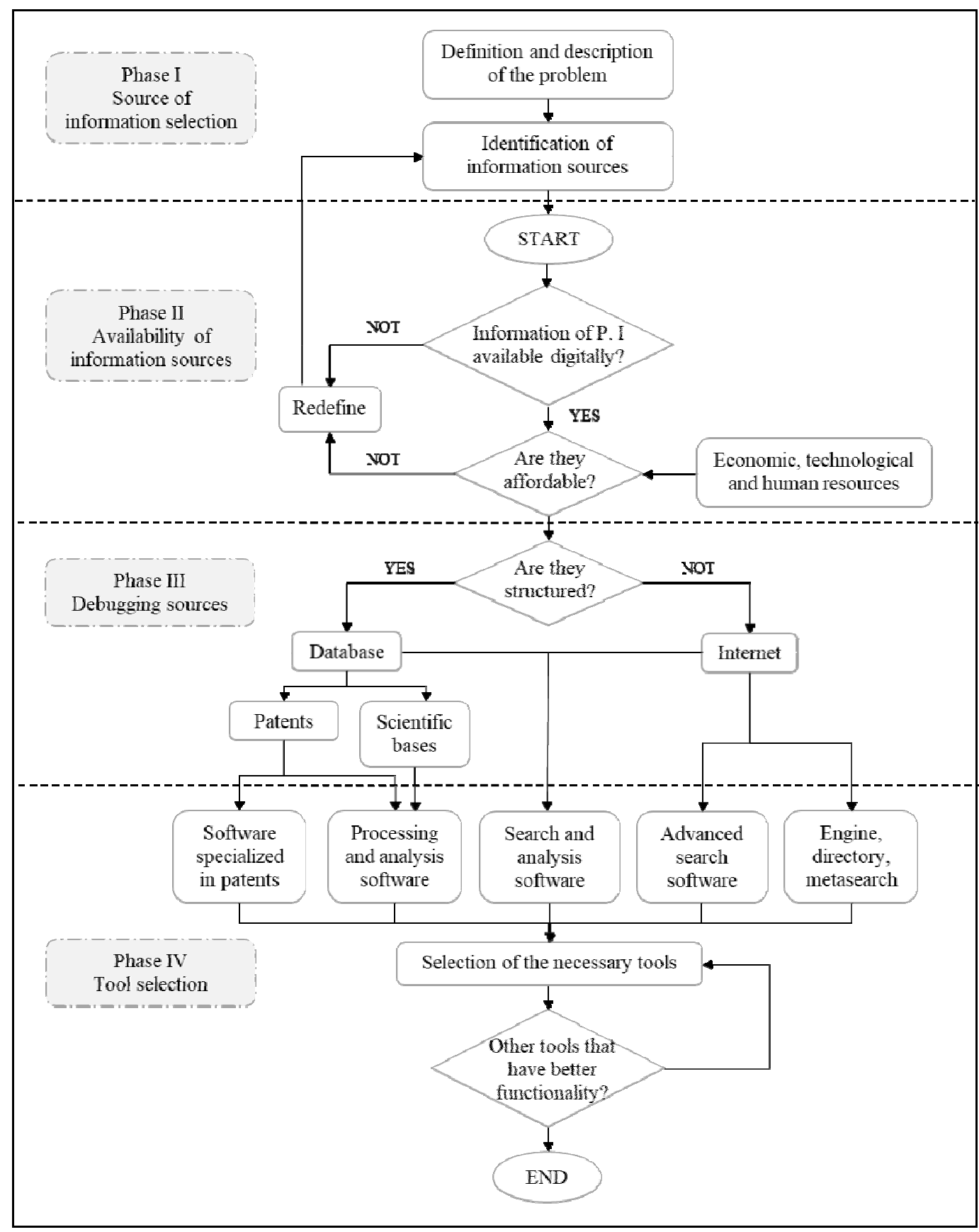

Fig. 2.Methodology for the selection of software tools for technological vigilance - Adapted from [11] 


\section{DEVELOPMENT AND DISCUSSION}

Within the implementation of a Technological Surveillance System is very important to define the objectives to be achieved in the organization, either to innovate and / or find new value in their products, processes and services [8-9]. Once these objectives are established, each of the stages that make up the technological surveillance process must be carried out (See Fig. 3), which are described below:

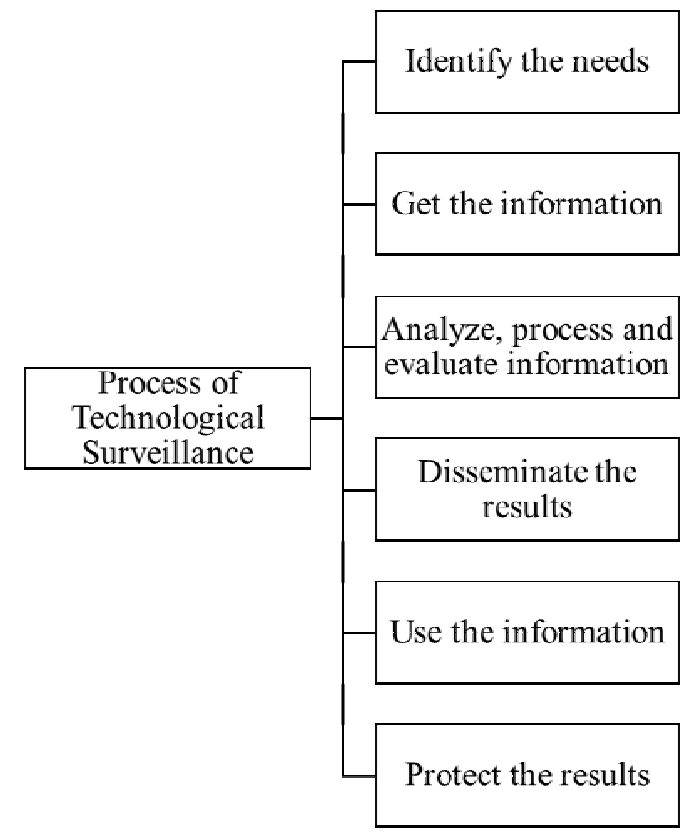

Fig. 3. Process of Technological Surveillance

1. Identify the needs of the organization in terms of information, which should be aligned with the interests of the company. To carry out this phase, the technological surveillance systems will rely on the heterogeneous and distributed sources that provide the most accurate data.

2. Obtain the information: an effective search must be carried out that implies the use of sources that contain the most suitable contents for the subsequent transformation of data into intelligent information; in these cases one can also choose to look for information within the organization itself (process data, historical data, etc.).

3. Analyze, process and validate the information: once the information has been located through the use of different sources and environments, it is necessary to evaluate the quality and reliability of it so that its use can be determined. The development of this phase is considerably important, since this depends on the success of a system, since the objective is to offer reliable information in a relevant way to the right areas and at the right times.

4. Disseminate the results: Once the information has been validated and it is considered useful, it must be distributed among the interested parties in a clear and friendly manner, through simple reports that allow the information to be displayed in a timely manner so that it is more easy analysis and decision making by the people in charge.

5. Use the information: It is important that the information collected and classified is put to use to avoid or minimize the risk in the decision making within the organization and to correct the progress of the projects that are being executed.

6. Protect the results: After executing each one of the previous phases, it is necessary to protect the results, that is to say the reports of technological surveillance since not all the times this information is made public for all the stakeholders, it is also important in this phase evaluating the results of the reports to determine if the needs that were raised at the beginning of the process were addressed in their entirety and in an appropriate manner or if there were aspects to improve or redirect to make a process more effective. (See Table I) 
TABLE I. Example of technological surveillance report according to UNE 166006: 2018

\begin{tabular}{|l|l|}
\hline \multicolumn{1}{|c|}{ CONTENT } & \multicolumn{1}{c|}{ DESCRIPTION } \\
\hline Anticipation & Proposed anticipatory decisions \\
\hline Take advantage of opportunities & Identification of new opportunities for the organization \\
\hline Risk reduction & Identification and analysis of threats to the organization \\
\hline Lines of improvements & $\begin{array}{l}\text { Improvements to overcome shortcomings and minimize weaknesses in } \\
\text { the projects of the organization }\end{array}$ \\
\hline Innovation & Proposals for ideas and new projects based on the analysis carried out \\
\hline Cooperation & Identification of potential collaborators \\
\hline
\end{tabular}

\section{CONCLUSIONS}

The use of tools or software for the implementation of a technological surveillance system proves to be effective for the organizations, since they allow capturing, filtering and analyzing the information in a precise way in order to determine the state of the art of the processes, technology or what one want information of or be aware of.

Therefore, in this document an analysis was initially carried out regarding the Technological Surveillance Systems, emphasizing the management elements at the moment of carrying out the surveillance process. Likewise, a methodology aimed at the identification of software tools for technological surveillance was referenced, which allows evaluating general attributes regarding the sources of information and selecting the most appropriate tool that fits the need; this with the aim of putting these tools into use, obtaining reliable information, at the precise moment to reach the right people, in order to make sound decisions that allow innovation and find new value in products, processes and / or services within the organization.

\section{ACKNOWLEDGMENT}

This work was supported by the Universidad Distrital Francisco José de Caldas FacultadTecnológica. The views expressed in this paper are not necessarily endorsed by the University. The authors thank the research group ARMOS for the evaluation carried out on prototypes of ideas and strategies.

\section{REFERENCES}

[1] Nosella, A., Petroni, G., Salandra, R.: Technological change and technology monitoring process: Evidence from four Italian case studies. In: Journal of Engineering and Technology Management, 25(4), pp. 321-337, 2008.

[2] Alnoukari, M., Hanano, A.: Integration of business intelligence with corporate strategic management. In: Journal of Intelligence Studies in Business, 7(2), pp. 5-16, 2017.

[3] Dou, H., Manullang, S.: Competitive Intelligence, Technology Watch and Regional Development, MUC Publishing, Jakarta, Indonesia, 2003.

[4] Zabala, J.: Innovation management tools: implementing technology watch as a routine for adaptation. In: Technology Analysis \& Strategic Management, 26(9), pp. 1073-1089, 2014.

[5] Meléndez, L., Orozco, Z.: Influencia de los agentes inteligentes en el proceso de vigilancia tecnológica. In: Gerencia Tecnológica Informática, 11(31), pp. 51-62, 2012.

[6] Dereli, T., Durmusoglu, A.: A trend-based patent alet system for technology watch. In: Journal of Scientific \& Industrial Research, 68, pp. 674-679, 2009.

[7] Veugelers, M., Bury, J., Viaene, S.: Linking technology intelligence to open innovation. In: Technological Forecasting and Social Change, 77(2), pp. 335-343, 2010.

[8] AENOR. Gestión de la I+D+i: Sistema de vigilancia e inteligencia. UNE 166006:2018. Asociación Española de Normalización y Certificación, Madrid, 2018.

[9] Surette, R.: The thinking eye: Pros and cons of second generation CCTV surveillance systems. In: Policing: An International Journal of Police Strategies \& Management, 28 (1), pp. 152-173, 2005.

[10] Martínez, F. \&Maynegra, E.: Evaluación de plataformas web para suimplementación en el sistema de vigilanciatecnológica de la ConsultoríaBiomundi. In: RevistaCubana de Información en Ciencias de la Salud, 25 (1), pp. 99-109, 2014.

[11] León A., Castellanos, O., Vargas, F.: Valoración, selección y pertinencia de herramientas de software utilizadas en vigilanciatecnológica. In. Ingeniería e Investigación, 26 (1); pp. 92-102, 2006. 